\title{
Primary Study of Aerodynamic Performance Evaluation and Optimiza- tion of the High-Speed Train
}

\author{
X. P. Wang, K. Cui*, S. C. Hu, T. Y. Gao, G. W. Yang \\ LHD of Institute of Mechanics Chinese Academy of Sciences, Beijing 100190, China
}

Email: Kcui@imech.ac.cn

\begin{abstract}
With the train speed becoming faster and faster, the aerodynamic drag turns to be one of the essential factor that restricts the train speed ascent. However, no public literature, home or abroad, has dealt with the flow field and aerodynamic performance of the train with the speed reaching $500 \mathrm{~km}$ per hour. This paper has studied in the flow field and the aerodynamic performance of the train at $500 \mathrm{~km}$ per hour with symmetrical and unsymmetrical nose shape. With the given two nose shape models, the authors composed four kinds train shapes and generated grids around the four train models. With the gathered and analyzed data, the paper comes to the conclusion that the unsymmetrical nose shape is better than the symmetrical one in aerodynamic performance. Comparing with the other three train shape, we found that the $s-r$ composition best satisfies the practical demands.
\end{abstract}

Key words: China Railways High-speed (CRH), nose shape, computational fluid mechanics, optimization

\section{INTRODUCTION}

Since the first high-speed train arised on Oct.1st, 1964, the high-speed railway has developed faster and faster. With the ascent of the train speed, the experts come to the conclusion that the higher the velocity is, the more intensive the aerodynamics impact exists on the train As a result, the relative problems on aerodynamics can not be neglected. Davis found that the aerodynamic drag is proportional to the square of the speed. Because of varies kinds of limitations of constrains, the track width, the train height and so on, the shape of train body hardly changes. Hence, it's better worth designing the reasonable train head for the high speed train to attain the destination of reducing the drag. This paper has focused on the aerodynamic performance of the train with different nose shape. With the method of computational fluid dynamics (CFD) of precision accuracy, the aerodynamic performance of trains running in $500 \mathrm{~km}$ per hour with symmetrical and unsymmetrical nose shape has been calculated. By analyzing the aerodynamic performance, we found the best composition satisfying the practical demands, which will provide reliable design reference for the practical design.

\section{COMPUTAIONAL MODELS}

With the two nose shape models, there come four kinds of composition, namely $r-r, r-s, s-r, s-s$. Here the first letter means the head shape; the latter one refers to the tail shape. The cross character of the middle car is the same with the back of the nose shape.The computational fluid mechanics software FLUENT has been used to obtain the numerical solution of the three dimension N-S equations with the fluid compressible and the $k$ - $\omega$ turbulent model, velocity $V=500 \mathrm{~km} / \mathrm{h}$, pressure $P=101325 \mathrm{pa}$, temperature $T=288.15 \mathrm{~K}$, reference cross area $\mathrm{A}=4.6615 \mathrm{~m}^{2}$.

Table 1 .The geometry parameter of the two nose shape models

\begin{tabular}{lcc}
\hline & Head length $(\mathrm{mm})$ & Streamlined head length $(\mathrm{mm})$ \\
\hline Rocket & 26250 & 12000 \\
Sword & 26750 & 12000 \\
\hline
\end{tabular}




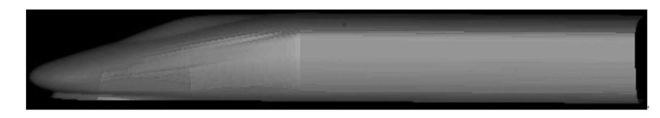

Figure 1: Socket model

Figure 3: Rocket-rocket $(r-r)$

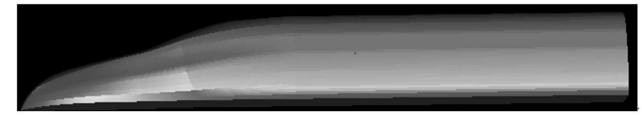

Figure 2: Sword model

Figure 4: Rocket-sword $r$-s

\section{THE RESULT AND ANALYSIS}

Figure 5 has described the pressure field around the $r$-s composition. Air from the far field gradually slows down and flows to up and down direction when it approaches the nose sharp. On the nose sharp, the speed has been reduced to 0 and there comes the stagnation and the high pressure area. The down-flowing air begins to speeds up and once again the speed slow down to 0 in the cowcatcher, and then the air reaches the gap between the cowcatcher and the subgrade where the air reaches the fastest speed due to the decrease of the flow area. The up-flowing air speeds up along the up surface of the head and there conforms the other less high-pressure area because of the slight angle between the train head and the cab front window, where the air flow has been quickened again and reaches the fastest on the maximum curvature at the train roof. There exist some eddies around the tail area which course the pressure drop. As a result, the aerodynamic drag increases.

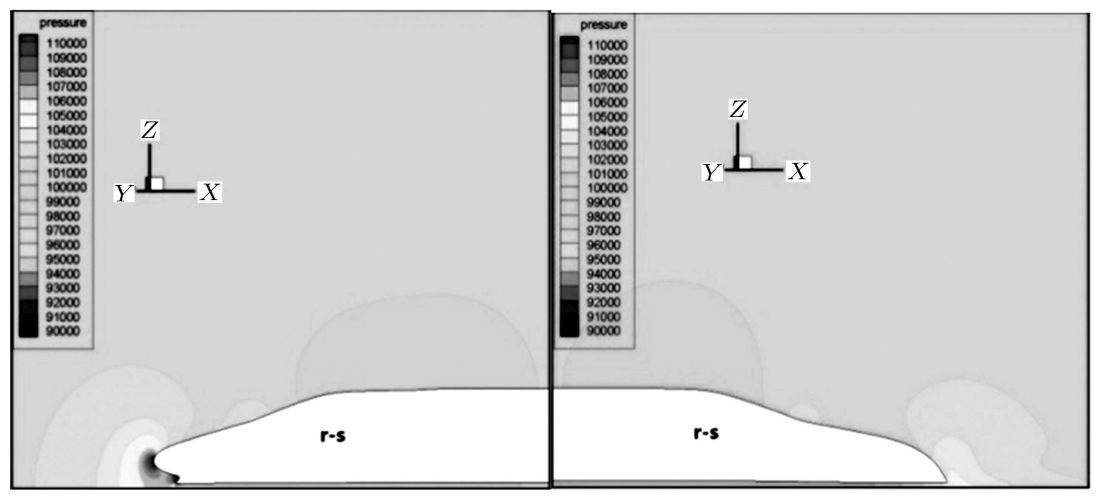

Figure 5: The pressure field of around $r-s$ composition

It is concluded from Figure 6 that the head accounts for nearly 50 percent of the total drag coefficients in all compositions and the middle car takes the least proportion. As a result, it's more effective to reduce the head drag to achieve the aim to reduce the total drag coefficient. What's more, the coefficient of the rocket head is bigger than the sword head by $2.3 \%$ and Figure 7 illustrates the reason. It's known that drag coefficient can be clarified into two parts, the pressure difference drag and the viscous drag. Figure 7 depicts that the pressure difference drag coefficient on rocket head is more than that of the sword head by $11.1 \%$, while the viscous drag coefficient for the two head are nearly the same. It is the pressure difference drag that course the main head drag differences. By changing the large parameters of the nose shape, the aerodynamic drag coefficient can be reduced. Based on this analysis, it's more favorable to take the sword as the train head.

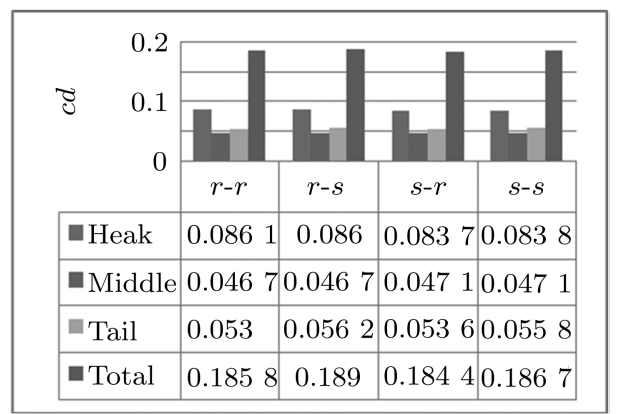

Figure 6: Drag distribution of the four composition

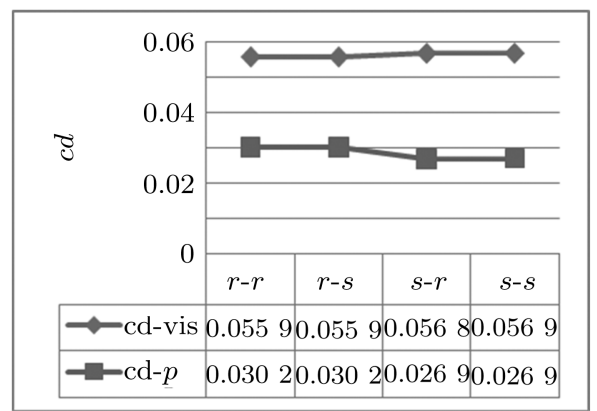

Figure 7: Head drag distribution for the four compositions 
From the computing results, we found that the absolute value of rocket lift is around 0.01 while the absolute value of the sword is around 0.08. It is widely recognized that the less the lift absolute value, the better the aerodynamic performance is. Based on this experience, it's more advantageous to choose the sword as the train tail.

From the analysis above, it is conclude that the drag coefficient of rocket head is bigger than that of the sword head. And the absolute value of lift coefficient of rocket tail is smaller than that of the sword tail. Consequently, it is clear that sword is more suitable for the head and the rocket for the tail and the unsymmetrical composition is more advantageous than the symmetrical composition. By properly composed, the unsymmetrical composition can take the advantages of the both nose shape which can provide some valuable reference for the practical design.

\section{Acknowledgements}

The support of National Natural Science Foundation of China (90916013) is gratefully acknowledged.

\section{REFERENCES}

1. Liang XF, Zhang J. Investigation of real train test into the air pressure distribution on external surface of power car. Jouranl of Changsha Railway University, 1000-2499(2002)04-0089-05

2. Chris B. The flow around high speed trains. Journal of Wind Engineering and Indrustrial Aerodynamics, J. Wind Eng. Ind. Aerodyn., 2010; 98: 277-298

3. Chen NY, Zhang J. Experimental investigates on aerodynamics drag of high speed train. Journal of the China Railway Society, 1986 